\title{
Prediction of Significant Wave Height along Konyaaltı Coast
}

\author{
Rifat Tur ${ }^{a}$, Dilayda Soylu Pekpostalci ${ }^{b}$, Özen Arlı Küçükosmanoğlu ${ }^{c}$, Alp Küçükosmanoğlu ${ }^{d^{*}}$ \\ ${ }^{a, b}$ Akdeniz University, Engineering Faculty, Antalya-TURKIYE \\ ${ }^{c, d}$ Mehmet Akif Ersoy University, Engineering-Architecture Faculty, Burdur-TURKIYE \\ ${ }^{*}$ E-mail address: alpkosmo@gmail.com \\ ORCID numbers of authors:

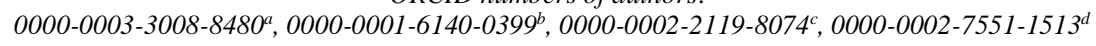

Received date: December 2017

Accepted date: December 2017

\begin{abstract}
Prediction of wave parameters is important for the planning, designing, construction and maintenance of coastal structures. In this study, significant wave heights $\left(H_{s}\right)$ for Konyaalt coast, located in Antalya at Mediterranean Sea coastline of Turkey is predicted. Significant wave height estimation is performed based on the wind data set which is obtained from The European Centre for Medium-Range Weather Forecasts (ECMWF) and Turkish State Meteorological Service (TSMS) by numerical and parametric methods in literature including WAM, CEM, Wilson and SMB method. While 13 years of wind data obtained from ECMWF is used for WAM and CEM method, 30 years of wind data provided from TSMS is used for SMB and Wilson method. The accuracy of these methods is investigated by comparing the Gumbel distribution results with Wind and Deep Water Wave Atlas for Turkish Coast for Konyaalt Coast. Consequently, CEM method provides more consistent results for the study area compare to other significant wave height prediction methods.
\end{abstract}

Keywords: Wave hindcasting, Significant wave height, SMB, Wilson, CEM, WAM

\section{Introduction}

Significant wave height which has an important role in coastal activities such as planning, designing of coastal structures, sediment transport and coastal erosion can be predicted by different methods including artificial intelligence techniques, numerical models, parametric methods etc. [1-8]. There are many studies in literature related to significant wave height estimation. While Duan et al. (2016) use a hybrid Empirical Model Decomposition (EMD) Support Vector Regression (SVR) model for short term, Altunkaynak (2015) uses spatial function for significant wave height prediction [9, 10]. Classification and regression trees are used by Mahjoobi and Etemad-Shahidi, an enhanced TakagiSugeno-based fuzzy methodology is used by Hashim et al., and also genetic algorithm is used by Elbisy [11-13]. Moreover, while Wang proposes transformed linear simulation method, Rusu and Raileanu uses a wave modelling system based on the simulating waves nearshore for significant wave height prediction $[14,15]$.

Wind wave characteristic is necessary for wave hindcasting. Since numerical modelling which solves the energy balance equation along the area where active wave generation occurs requires the bathymetric, meteorological and oceanographic data. Since numerical modelling is expensive and difficult in the absence of these data, several simplified methods including SMB (Sverdrup, Munk and Bretschneider) (Bretschneider 1970), Wilson (Wilson 1965), JONSWAP (Haselman et al. 1973), 
Donelan (Donelan 1980), SPM (Shore Protection Manual) (U.S. Army 1984), CEM (Coastal Engineering Manual) (U.S. Army 2006) are used [16].

The studies on significant wave height estimation by parametric models including Wilson, SPM, JONSWAP, and CEM for the south of Black Sea indicate that although CEM method provides better results than the others, parametric methods are unable to provide sufficient result. However, ANFIS models provide more accurate results than the parametric methods [17, 18]. Dubey and Das (2013) indicates that after significant wave height for Indian Coast is estimated by CEM and Wilson method the extreme wave analysis is done by Gumbel, Weibull and log-normal distribution methods [19]. Balas et al. (2013) present significant wave height prediction by CEM method and Gumbel distribution for Edremit, Balıkesir by use of HYDROTAM-3D [20]. Etemad-Shahidi et al. compare the results of CEM, Wilson and SMB methods with the measured wave heights for Great Lakes and investigate the accuracy of each model for different conditions [16].

The aim of this study is to compare extreme value analysis with Gumbel distribution obtained from four different significant wave height prediction methods including WAM (A third generation ocean wave prediction model), CEM, Wilson and SMB methods.

\section{Material and Methods}

\subsection{Study Area and Dataset Description}

The data set for Konyaalt1 coast, located in Antalya at Mediterranean Sea coastline of Turkey at $30.70^{\circ} \mathrm{E} 36.84^{\circ} \mathrm{N}, 30.66^{\circ} \mathrm{E}$ (Fig. 1) is obtained from both ECMWF and Turkish State Meteorological Service.

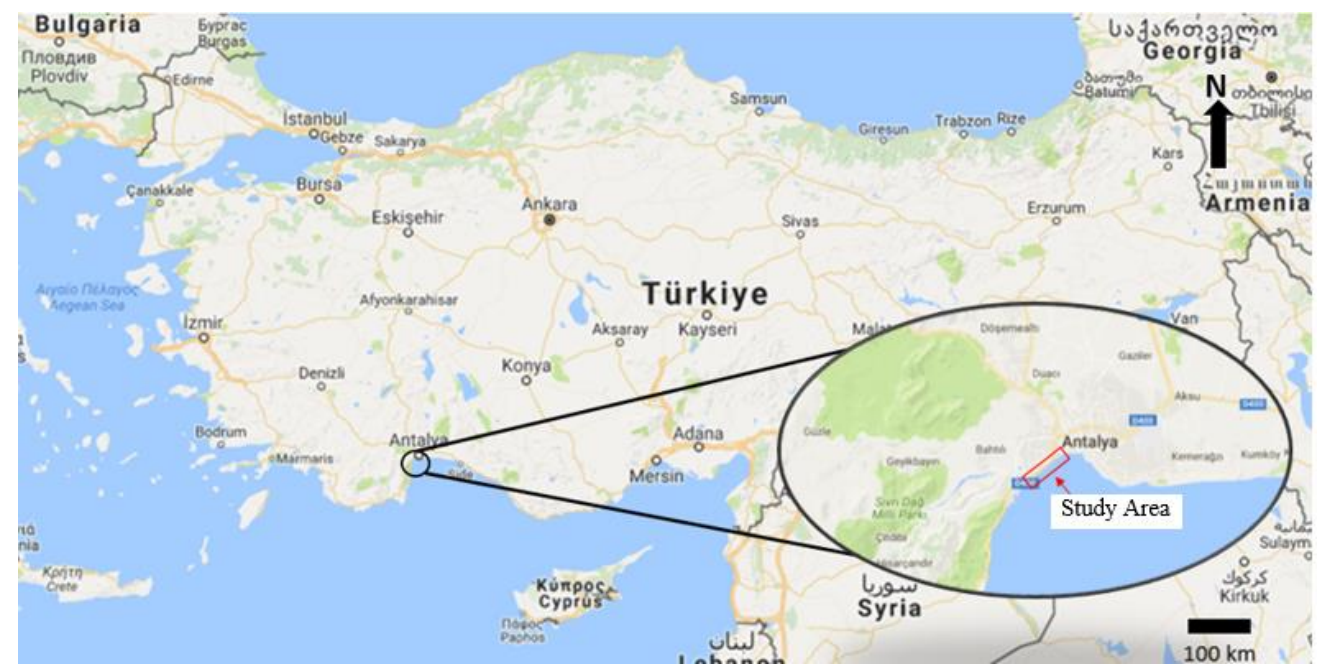

Fig. 1. Location of study area

Approximately 30 years of hourly wind data acquired from Turkish State Meteorological Service. The data set is composed of station 17300 (from June, 1981 to December, 2006) and station 17302 wind data (from January, 2012 to March, 2016). 13 years of 6 hourly wind data (from 2000 to 2013) is obtained from ECMWF. While 13 years of ECMWF wind data is used for WAM and CEM method, 30 years of wind data provided from TSMS is used for SMB and Wilson method. 


\subsection{Methodology}

While WAM model is numerical, the other methods are parametric methods. All methods can be used for wave hindcast or forecast. Also the comparative results obtained from WAM, CEM, Wilson and SMB methods are presented.

First of all, fetch length and wind duration are needed to determine whether the fully developed state occurs or not. If wind transfers maximum energy to wave, then fully developed sea condition occurs. Otherwise, duration limited condition occurs when wind duration is smaller than $t_{\min }$ or fetch limited condition occurs when fetch length is smaller than $\mathrm{F}_{\min }$. Since fetch or duration is inadequate to that wind is able to impart maximum energy to wave, sea is non-fully developed state for both duration and fetch limited condition.

The effective fetch length $\left(F_{\text {eff }}\right)$ which is commonly used in literature is determined according to the location of study area. For each wind direction, fetch lengths $\left(F_{i}\right)$ are measured extend over $45^{\circ}$ range either side of wind direction for each 7,50 interval $\left(\alpha_{i}\right)$. By this way, measured 12 fetch lengths and 12 angles for the wind direction are used to calculate effective fetch length [21] :

$$
F_{\text {eff }}=\frac{\sum F_{i} \cos ^{2} \alpha_{i}}{\sum \cos \alpha_{i}}
$$

Since wind velocity higher than $3 \mathrm{~m} / \mathrm{s}$ is considered for Wilson and SMB method, wind duration is determined according to duration of wind blowing that velocity of wind is higher than $3 \mathrm{~m} / \mathrm{s}$. And wind speed at $10 \mathrm{~m}$ above the sea $\left(U_{10}\right)$ is used for the methods presented in the following parts. If wind speed is observed at any elevation up to $20 \mathrm{~m} \mathrm{Eq.} \mathrm{(2)} \mathrm{can} \mathrm{be} \mathrm{used} \mathrm{[22]:}$

$$
U_{10}=U_{z}\left(\frac{10}{z}\right)^{\frac{1}{7}}
$$

Additionally, stability correction due to the air-sea temperature difference Eq. (3) and location effect due to surface roughness Eq. (4) proposed by Resio and Vincent (1977) can be used where needed [22]:

$$
\begin{aligned}
& U=R_{T} U(10) \\
& U_{w}=R_{L} U_{L}
\end{aligned}
$$

After gathering the $\mathrm{U}_{10}$ values, significant wave heights are calculated. First of all, it should be determined that the case is fetch limited, duration limited or fully developed. So significant wave height are calculated according to formulation that differs in these cases. Since results obtained from SMB, Wilson, CEM, and WAM methods indicate the extreme value analysis for Konyaaltı coast, the comparative results are shown by Gumbel distribution for each method. 


\subsubsection{SMB}

If wind duration is greater than $t_{\min }, \mathrm{H}_{\mathrm{s}}$ is calculated by Eq. (5) in case fetch limited condition. Otherwise, case is duration limited and Eq. (6) is used to find corresponding fetch for duration limited cases, and then $\mathrm{H}_{\mathrm{s}}$ is calculated by Eq. (6).

$$
\begin{gathered}
\frac{g H_{s}}{U_{10}^{2}}=0,283 \tanh \left(0,0125\left(\frac{g F}{U_{10}^{2}}\right)^{0,42}\right) \\
\frac{g t_{\min }}{U_{10}}=6,5882 \exp \left\{\left[0,0161\left(\ln \left(\frac{g F}{U_{10}^{2}}\right)\right)^{2}-0,3692\left(\ln \left(\frac{g F}{U_{10}^{2}}\right)\right)+2,2024\right]^{0,5}+0,8798\left(\ln \left(\frac{g F}{U^{2}}\right)\right)\right\}
\end{gathered}
$$

where $g$ is acceleration due to gravity $\left(\mathrm{m} / \mathrm{s}^{2}\right), F$ is the fetch length $(\mathrm{m}), U_{10}$ is the wind speed at $10 \mathrm{~m}$ above the sea surface $(\mathrm{m} / \mathrm{s}), t_{\min }$ is the minimum duration $(\mathrm{hr})$,

\subsubsection{Wilson}

In this method, minimum duration $\left(t_{\min }, \mathrm{hr}\right)$ and minimum fetch length $\left(F_{\min }, \mathrm{km}\right)$ are calculated by the Eq. (7) and Eq. (8):

$$
\begin{gathered}
t_{\text {min }}=1,0 F^{0,73} U_{10}^{-0,46} \\
F_{\text {min }}=1,0 t^{1,37} U_{10}^{0,63}
\end{gathered}
$$

where, $F$ is the fetch length $(\mathrm{km}), U_{10}$ is the wind speed at $10 \mathrm{~m}$ above the sea surface $(\mathrm{m} / \mathrm{s}), t$ is wind duration (hr).

The significant wave height is calculated by Eq. (9) in the fetch limited condition:

$$
\frac{g H_{s}}{U_{10}^{2}}=0,30\left[1-\left[1+0,004\left(\frac{g F}{U_{10}^{2}}\right)^{0,5}\right]^{-2}\right]
$$

where $g$ is acceleration due to gravity $\left(\mathrm{m} / \mathrm{s}^{2}\right)$.

Otherwise, in the duration limited condition significant wave height is calculated with equivalent fetch which is defined by replacing $t_{\min }$ by $t$ in Eq. (7) 


\subsubsection{CEM}

In the CEM method [23] the minimum wind duration $\left(t_{\min }, \mathrm{s}\right)$ formulation is expressed by Eq. (10):

$$
t_{\min }=77,23 \frac{F^{0,67}}{U_{10}^{0,34} g^{0,33}}
$$

where $F$ is the fetch length $(m), U_{10}$ is the wind velocity above $10 \mathrm{~m}$ from the sea surface $(\mathrm{m} / \mathrm{s}), g$ is the acceleration of gravity $\left(\mathrm{m} / \mathrm{s}^{2}\right)$.

For fetch limited condition $H_{s}$ is calculated by Eq. (11):

$$
\frac{g H_{s}}{u_{*}^{2}}=4,13 \times 10^{-2}\left(\frac{g F}{u_{*}^{2}}\right)^{0,5}
$$

where $\mathrm{u}_{*}$ is the friction velocity $(\mathrm{m} / \mathrm{s})$ estimated by Eq. (12):

$$
u_{*}=U_{10}\left(C_{D}\right)^{0,5}
$$

where, $C_{D}$ is the drag coefficient which is calculated by Eq. 13

$$
C_{D}=0,001\left(1,1+0,035 U_{10}\right)
$$

In duration limited condition equivalent fetch length is calculated by:

$$
\frac{g F}{U_{*}^{2}}=5,23 \times 10^{-3}\left(\frac{g t}{U_{*}}\right)^{1,5}
$$

\subsubsection{WAM}

WAM which is a third generation wave model is presented by The Wave Model Development and Implementation Group (WAMDI Group); is the first model that solves the energy balance equation, including non-linear wave interactions [23-25]. Wave forecast with WAM model is proceeded as follows [24]:

Evolution equation for action density $N(k)$ is presented by Eq. (15): 


$$
F(k)=\sigma N(k)
$$

where $F(k)$ is wave number spectrum, $k$ is the wave number and $\sigma$ is calculated by Eq. (16):

$$
\sigma=\sqrt{g k \tanh k D}
$$

where $D$ is the water depth and $g$ is the acceleration of gravity,.

Wave number spectrum is normalized with Eq. (17):

$$
\int d k F(k)=\left\langle\eta^{2}\right\rangle=m_{0}
$$

where $\eta$ is the surface elevation and $m_{0}$ is the wave variance.

Significant wave height is calculated by Eq. (18):

$$
H_{s}=4 \sqrt{\left\langle\eta^{2}\right\rangle}
$$

The frequency spectrum is defined as:

$$
F_{2}(\omega, \theta) d \omega d \theta=F(k) d k=F(k, \theta) k d k d \theta
$$

where $\theta$ is the wave direction.

The one dimensional frequency spectrum is defined by Eq. (20):

$$
F_{1}(\omega)=\int d \omega F_{2}(\omega, \theta)
$$

For fully developed waves Eq. (21) is used:

$$
g^{3} F(\omega) / U_{10}^{5}=f\left(\omega U_{10} / g\right)
$$

For fetch limited conditions Eq. (22) is used:

$$
g^{3} F(\omega) / U_{0}^{5}=f\left(\omega U_{10} / g, g F / U_{10}^{2}\right)
$$

where $F$ is the fetch length. 


\section{Application and Results}

Parametric methods SMB, Wilson, CEM and numerical method WAM are used to predict significant wave height for Konyaaltı Coast. While 30 years of hourly wind data provided from TSMS is used for SMB and Wilson method, 13 years of 6 hourly ECMWF wind data is used for WAM and CEM methods. Table 1 indicates the significant wave heights $(\mathrm{m} / \mathrm{s})$ corresponding to return period (year) for each method.

Table 1. Significant Wave Heights $(\mathrm{m} / \mathrm{s})$

\begin{tabular}{llllll}
\hline Tr(year) & $\mathbf{5}$ & $\mathbf{1 0}$ & $\mathbf{2 0}$ & $\mathbf{5 0}$ & $\mathbf{1 0 0}$ \\
\hline SMB & 3,6 & 4,24 & 4,86 & 5,66 & 6,26 \\
GODA & 1,98 & 2,37 & 2,74 & 3,23 & 3,59 \\
CEM & 4,57 & 5,23 & 5,86 & 6,67 & 7,28 \\
WAM & 3,26 & 3,67 & 4,06 & 4,57 & 4,95 \\
\hline
\end{tabular}

Gumbel distribution for each model is presented in Fig. 2 in order to indicate the comparative results. Gumbel distribution for Konyaaltı Coast $\left(36.75^{\circ} \mathrm{N}, 30.70^{\circ} \mathrm{E}\right)$ obtained from Wind and Deep Water Wave Atlas for Turkish Coast[26] is also presented to investigate the performance of the models (Fig. 2). " $q$ " in Fig. 2 which indicates the non-exceedance probability of significant wave height is calculated by Eq. (23).

$$
q=1-\frac{1}{T_{r}}
$$

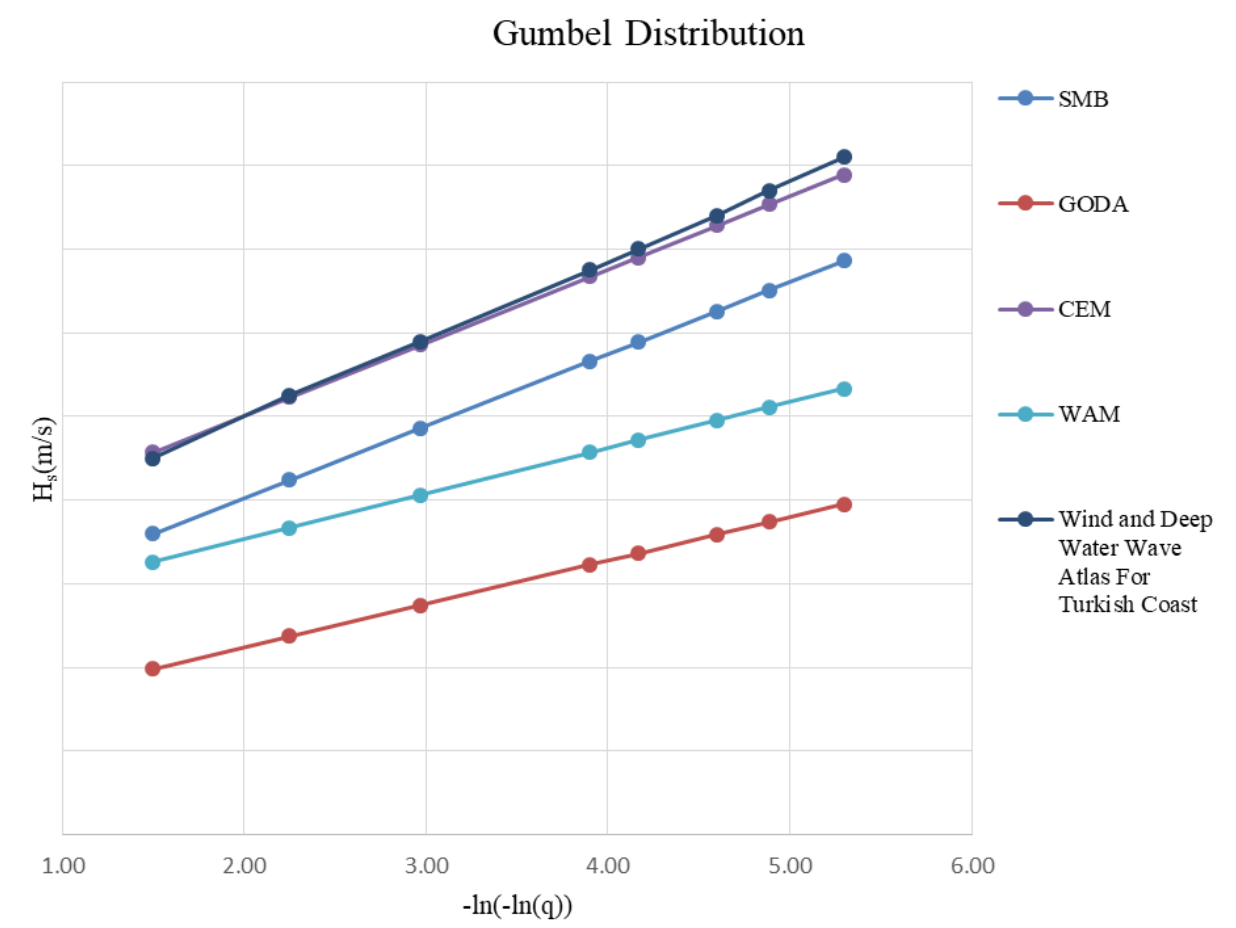

Fig. 2. Gumbel Distribution 
The results of CEM method and Wind and Deep Water Wave Atlas for Turkish Coast are closer compare to other methods. It can be easily seen that CEM method provides more consistent result with of Wind and Deep Water Wave Atlas for Turkish Coast for study area.

\section{Conclusions}

This study indicates the significant wave height prediction results of parametric and numerical methods including SMB, Wilson, CEM, and WAM. After significant wave heights are predicted, extreme value analysis with Gumbel distribution is done for each method. Gumbel distributions are presented in the same graph (Fig. 2) in order to examine similarities between results. Gumbel distribution of Wind and Deep Water Wave Atlas for Turkish Coast for Konyaaltı Coast is given to investigate the performance of methods used. Consequently, CEM method provides more consistent results with Wind and Deep Water Wave Atlas for Turkish Coast for study area as compared to the other significant wave height prediction methods. Also, 13 years of wind data gives higher significant wave height values compared to 30 years of wind data considering the gumbel distributions of these data sets. This situation can be result from climate change.

\section{References}

[1] Berbic, J., Ocvirk, E., Carevic, D., Loncar, G., Application of neural networks and support vector machine for significant wave height prediction. Oceanologia, 59(3), 331-349, 2017.

[2] Cornejo-Bueno, L., Borge, J.C.N., Alexandre, E., Hessner, K., Salcedo-Sanz, S., Accurate estimation of significant wave height with Support Vector Regression algorithms and marine radar images. Coastal Engineering, 114, 233-243, 2016.

[3] Cornejo-Bueno, L., Nieto-Borge, J.C., Garcia-Diaz, P., Rodriguez, G., Salcedo-Sanz, S., Significant wave height and energy flux prediction for marine energy applications: A grouping genetic algorithm - Extreme Learning Machine approach. Renewable Energy, 97, 380-389, 2016.

[4] Orimolade, A.P., Haver, S., Gudmestad, O.T., Estimation of extreme significant wave heights and the associated uncertainties: A case study using NORA10 hindcast data for the Barents Sea. Marine Structures, 49, 1-17, 2016.

[5] Shukla, R.P., Kinter, J.L., Subseasonal Prediction of Significant Wave Heights over the Western Pacific and Indian Ocean Region. Weather and Forecasting, 31(6), 1733-1751, 2016.

[6] Tür, R., Belirgin Dalga Yüksekliğinin (Significant Wave Height= $\mathrm{H}_{\mathrm{s}}$ ) Bulanık Sinir Ağları (ANFIS) ile Tahmini. The Journal of Graduate School of Natural and Applied Sciences of Mehmet Akif Ersoy University 7(2), 175-183, 2016.

[7] Yu, T.T., Xie, W.S., Zhang, S.O., Improved algorithm for estimation of significant wave height from Xband radar image sequences. Journal of Applied Remote Sensing, 10, 2016.

[8] Zhang, S., Song, Z.J., Lie, Y., An advanced inversion algorithm for significant wave height estimation based on random field. Ocean Engineering, 127, 298-304, 2016.

[9] Altunkaynak, A., Prediction of significant wave height using spatial function. Ocean Engineering, 106, 220-226, 2015.

[10] Duan, W.Y., Han, Y., Huang, L.M., Zhao, B.B., Wang, M.H., A hybrid EMD-SVR model for the shortterm prediction of significant wave height. Ocean Engineering, 124, 54-73, 2016.

[11] Elbisy, M.S., Sea Wave Parameters Prediction by Support Vector Machine Using a Genetic Algorithm. Journal of Coastal Research, 314, 892-899, 2015.

[12] Hashim, R., Roy, C., Motamedi, S., Shamshirband, S., Petković, D., Selection of climatic parameters affecting wave height prediction using an enhanced Takagi-Sugeno-based fuzzy methodology. Renewable and Sustainable Energy Reviews, 60, 246-257, 2016.

[13] Mahjoobi, J., Etemad-Shahidi, A., An alternative approach for the prediction of significant wave heights based on classification and regression trees. Applied Ocean Research, 30(3), 172-177, 2008. 
[14] Rusu, E., Raileanu, A., A multi-parameter data-assimilation approach for wave prediction in coastal areas. Journal of Operational Oceanography, 9(1), 13-25, 2016.

[15] Wang, Y.-g., Prediction of height and period joint distributions for stochastic ocean waves. China Ocean Engineering, 31(3), 291-298, 2017.

[16] Etemad-Shahidi, A., Kzeminezhad, M.H., Mousavi, S.J. On The Prediction of Wave Parameters Using Simplified Methods.Journal of Coastal Research, Portugal, 2009.

[17] Akpınar, A., Özger, M., Kömürcü, M.İ., Prediction of wave parameters by using fuzzy inference system and the parametric models along the south coasts of the Black Sea. Journal of Marine Science and Technology, 19(1), 1-14, 2014.

[18] Akpinar, A., Özger, M., Bekiroglu, S., Komurcu, M.I., Performance Evaluation of Parametric Models in The Hindcasting of Wave Parameters Along The South Coast of Black Sea. Indian Journa og GeoMArine Sciences, 43(6), 905-920, 2014.

[19] Dubey, R.P., Das, B., Long Term Ocean Wave Forecasting Along Indian Coast Journal of Indian Water Resources Society, 33(2), 24-29, 2013.

[20] Balas, L., Numanoğlu Genç, A., İnan, A., Liman yapılarının tasarımı için dalga tahmini. Dokuz Eylül Üniversitesi Denizcilik Fakültesi Dergisi, 5(2), 2013.

[21] Yüksel, Y., Özkan Çevik, E., Kıyı Mühendisliği, 1 ed, Deniz Mühendisliği Serisi - No12009, İstanbul; Beta basim yayım,2009.

[22] Shore Protectin Manual (SPM)1984, U. S. Army Corps of Engineers, Washington, DC: U.S. Army Engineer Waterways Experiment Station, U.S.; U. S. Government Printing Office, 1984.

[23] Coastal Engineering Manual. U. S. Army Corps of Engineers, U.S., 2006.

[24] Janssen, P., The Wave Model. Meteorological Training Course Lecture Series, 2003.

[25] The WAMDI Group, The WAM Model - A third Generation Ocean Wave Prediction Model. Journal of Physical Oceanography, 18, 1775-1810, 1988.

[26] Özhan, E., Abdalla S., Türkiye klyıları rüzgar ve derin deniz dalga atlası, MEDCOAST, METU, 445,2002 . 